\title{
TÉCNICAS DE SENSORIAMENTO REMOTO PARA O ESTUDO DO USO E OCUPAÇÃO DAS TERRAS DO MUNICÍPIO DE CARDOSO MOREIRA $-\mathbf{R J}$
}

Guilherme Ignácio Reis $^{(\mathrm{a})}$, Alex Gustavo Pinheiro ${ }^{(\mathrm{b})}$

(a) Departamento de Geografia/ Universidade Federal Fluminense, reisig.guilherme@gmail.com

(b) Departamento de Geografia/ Universidade Federal Fluminense, alex.gustavo.ferreira@ gmail.com

Eixo: Uso e ocupação das terras e legislação ambiental

\begin{abstract}
Resumo
O trabalho aborda o processo de tratamento de imagens orbitais do município de Cardoso Moreira, localizado na Região do Norte Fluminense, através de técnicas de Processamento digital de imagens e Sensoriamento remoto utilizando o software SPRING.A manipulação das imagens tem por objetivo a produção de um mapa de uso e ocupação do solo. É um importante instrumento de análise e interpretação do espaço, sendo de fundamental importância para se entender a organização antrópica, a existência de recursos naturais e bem como o uso desses.
\end{abstract}

Palavras Chaves: Uso e ocupação do solo; Cardoso Moreira; Processamento digital de imagens.

\section{Introdução}

A Região Norte Fluminense é caracterizada pelas fortes atividades envolvendo a agricultura e a pecuária. Em detrimento das modificações antrópicas no espaço o presente projeto se torna de suma importância para a análise do espaço e das mudanças significativas nesse território. O trabalho visa analisar o uso e ocupação das Terras do município de Cardoso Moreira. Para a confecção do produto cartográfico final, foi necessário a utilização de técnicas de Sensoriamento Remoto. Segundo (Jensen, 2012 p.14) "Sensoriamento Remoto é a arte e a ciência de obter informação sobre um objeto sem estar em contato direto físico com o objeto".

A escolha do município de Cardoso Moreira como a área a ser estudada, deve-se ao fato da recente emancipação em 1989. Como consequência direta, sofre com problemas ambientais, devido a carência de estudos científicos sobre o seu território.

\section{2. Área de Estudo}

O município de Cardoso Moreira localiza-se no norte do Estado do Rio de Janeiro e pertence a região do Norte Fluminense. Segundo o Censo Demográfico do IBGE (2010) a população era estimada em 12.600 habitantes, as principais atividades econômicas do município são agropecuárias e serviços. 


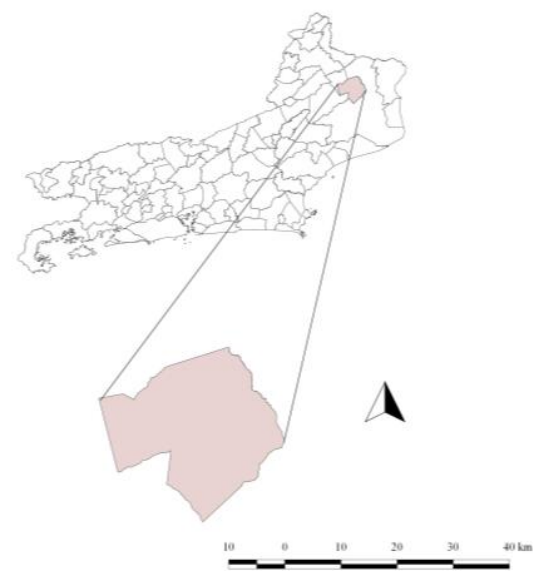

Figura 1 - Localização de Cardoso Moreira no estado do Rio de janeiro

\section{Metodologia}

\subsection{Obtenção da Imagem}

Para a realização deste estudo foi usada utilizada uma imagem do satélite Landsat- 8 , passagem no dia 16/06/2016, órbita 216, ponto 075.0 satélite foi escolhido por disponibilizar imagens gratuitamente, possuir uma passagem frequente e apresentar uma boa resolução espacial e espectral, que favorecem um contraste entre os alvos que serão classificados.

Foram escolhidas as bandas 6R/5G/4B com a composição em falsa-cor, a banda 4 é relacionada ao vermelho, a banda 5 ao IV próximo e a 6 ao IV distante. Segundo a Tabela 1, que apresenta dados disponibilizados pelo Serviço Geológico Dos Estados Unidos (USGS). As bandas escolhidas possuem os seguintes usos para o mapeamento:

Tabela I - Características das Bandas utilizadas

\begin{tabular}{lcl}
\hline Bandas & Comprimento de onda & Uso para o mapeamento \\
\hline Banda 4 - Red & $0.64-0.67 \mathrm{~nm}$ & $\begin{array}{l}\text { Maior discriminação para as vegetações } \\
\text { localizadas em encosta. }\end{array}$ \\
Banda 5 - Near Infrared & $0.84-0.88 \mathrm{~nm}$ & $\begin{array}{l}\text { Ênfase na biomassa presente no solo e } \\
\text { nas regiões costeiras }\end{array}$ \\
Banda 6 Short-wave Infrared \\
(SWIR)
\end{tabular}

Fonte: tradução livre dos autores. Link direto: https://landsat.usgs.gov/what-are-best-spectral-bands-use-my-study

O recorte do município de Cardoso Moreira se deu a partir da inserção do Shapefile de municípios do Norte Fluminense na imagem e a partir do mesmo recortamos o município de Cardoso Moreira. Para o processamento e classificação das imagens utilizou-se o programa SPRING. 


\subsection{Segmentação e classificação das imagens}

Após o recorte da área de estudo fez-se o realce de cada banda que será usada. Segundo Moreira (2012) O Realce é aplicado toda vez que se quer visualizar uma imagem de satélite e consiste na ampliação do contraste das feições da cena, fazendo uma manipulação dos níveis de cinza. Cada imagem possuí um histograma associado no qual apresenta estatisticamente a distribuição de frequencias dos níveis de tons de cinza. A técnica utilizada neste trabalho foi o realce linear.

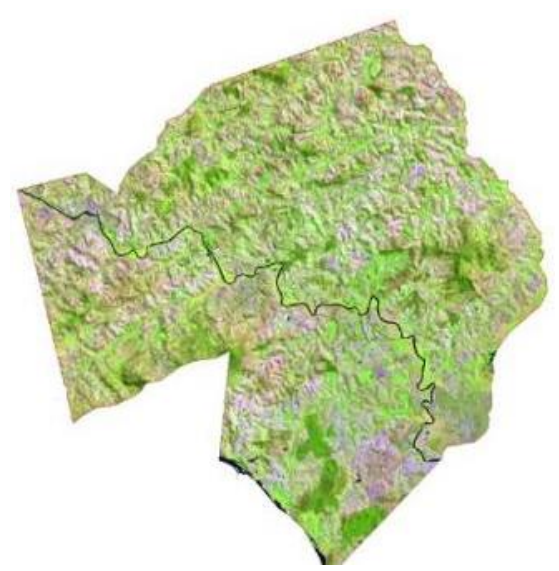

Figura 2: Imagem após a aplicação do realce.

Após o processo de realce da imagem, foi realizada a segmentação. Segundo Woodcock (1994), conforme citado por Moreira (2012,p.329) "O processo de segmentação de imagens tem por objetivo fragmentar uma região em unidades homogêneas, considerando algumas de suas características intrínsecas, a exemplo do nível de cinza dos pixels, da textura e do contraste."

O método de segmentação utilizado foi o Crescimento por regiões. Segundo Moreira (2012, p.329) essa técnica consiste em um agrupamento de regiões, podendo ser apenas um pixel ou conjunto de pixels, que são espacialmente adjacentes segundo um critério de similaridade.

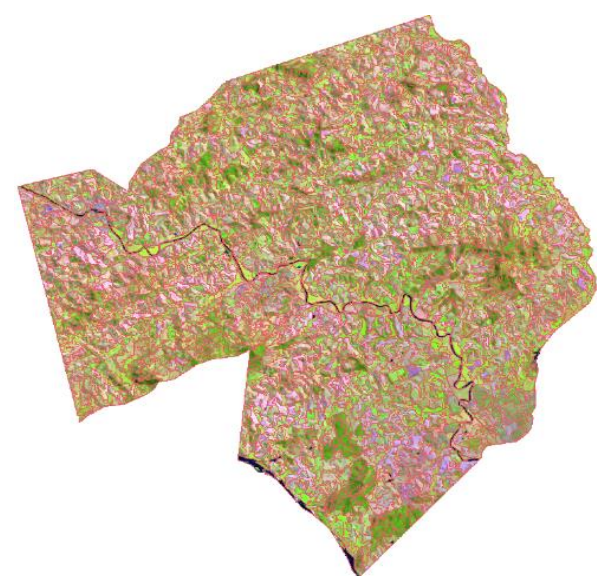

Figura 3: Imagem segmentada de coleta de regiões, para a realização da classificação.

Para a classificação, foi utilizado o classificador Bhattacharya. É um classificador supervisionado por regiões, que usa a distância Bhattacharya para diferenciar as características estatísticas entre as classes 
espectrais. "O classificador de Bhattacharya requer a seleção de áreas de treinamento, podendo utilizar as regiões obtidas pela segmentação ou polígonos representativos das regiões a serem classificadas. " (OLIVEIRA;VEROLA,2013,p.92).

Foram determinadas 6 classes para a classificação: Drenagem, Pastagem, Mata Ciliar, Mata Secundária, área Urbana e Cultura. O critério de escolha se baseou nas principais características ambientais e econômicas que ocupam a maior parte do solo municipal.

$\mathrm{Na}$ etapa do treinamento foram coletadas amostras de pixels, que correspondem as classes determinadas, após o termino da coleta o programa SPRING fez a classificação utilizando o classificador Bhattacharya. O layout do mapa foi desenvolvido no programa de Software Quantum Gis.

\section{Resultados e Discussões}

Com o mapa do uso do solo do município de Cardoso Moreira concluído, foi obtido dados acerca da área territorial de cada uma das classes, esses dados se encontram em formato de área total $\left(\mathrm{KM}^{2}\right)$ e porcentagens relativas (Figura 4; Tabela 2).

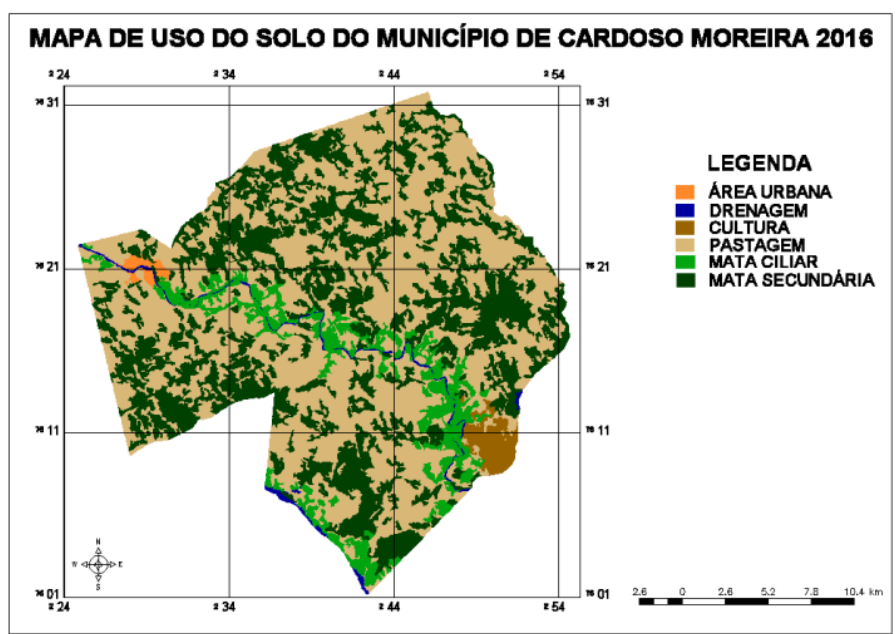

Figura 4: Mapa de uso e cobertura do solo de Cardoso Moreira.

Tabela II: Dados relacionados ao uso e ocupação do solo

\begin{tabular}{|c|c|c|}
\hline Classes & Áreas em KM & \multicolumn{2}{|c|}{ Porcentagem } \\
\hline Área Urbana & 8,4 & $1,70 \%$ \\
\hline Pastagem & 301,1 & $58,63 \%$ \\
\hline Cultura & 17,7 & $3,37 \%$ \\
\hline Drenagem & 5,4 & $1,28 \%$ \\
\hline Mata Ciliar & 103,0 & $19,37 \%$ \\
\hline Mata Secundária & 79,8 & $15,65 \%$ \\
\hline Área Total & 515,4 & $100,00 \%$ \\
\hline
\end{tabular}

É perceptível a predominância da atividade de pecuária (gado leiteiro), ocupando cerca de 58,63\% do território municipal, historicamente a área destinada ao pasto tende sempre a crescer no município. Essa 
expansão ocorre de modo desordenado, não respeitando as diretrizes ambientais nacionais, avança cada vez mais sob as áreas de mata (secundária e ciliar). O mapa mostra que as regiões de mata secundária se encontram dispostas em fragmentos separados por grandes extensões de pasto.

O rio Muriaé é o principal corpo hídrico do município, a mata ciliar não o recobre completamente, existem trechos em que o pasto ocupa o espaço da mata. A área urbana do município se encontra as margens do rio Muriaé, ocupando uma área de $8,4 \mathrm{KM}^{2}$, o centro urbano também exerce uma pressão sobre as áreas de mata ciliar, é perceptível a ausência de vegetação próxima a área urbana.

A área representada pela cultura, é uma área relativamente pequena e com base no site da prefeitura, os principais alimentos cultivados são cana de açúcar, aipim, feijão, jiló, tomate e banana

\section{Considerações Finais}

O trabalho buscou apresentar e analisar as principais características do uso do solo no município de Cardoso Moreira, para atingir tal objetivo, foi confeccionado um mapa de uso e ocupação do solo utilizando técnicas de sensoriamento remoto a partir de imagens orbitais.

Com os dados referentes a área territorial de cada uma das classes, obtidos a partir do mapa de uso e ocupação do solo, observou-se que por se tratar de um município recém emancipado e com características rurais, as atividades agropecuárias demandam uma grande parcela do solo no munícipio. As grandes áreas destinadas para a pecuária, avançam e exercem pressão sob regiões de mata nativa, intensificando o processo de desmatamento e fragmentação.

O mapa de uso e ocupação do solo se mostra uma ferramenta importante para o auxílio do planejamento municipal, por proporcionar a espacialização e identificação dos objetos, fenômenos ou processos, de características antrópicas e ambientais que ocorrem no território. Garantindo assim, a melhor utilização dos recursos naturais, numa relação em que ocorra suprimento das necessidades da população com o mínimo de impactos ambientais possíveis.

\section{Bibliografia}

IBGE Cidade, Cardoso Moreira. Disponível em <http://cidades.ibge.gov.br/xtras/perfil.php?codmun=330115>. Acesso em 20/07/2016.

Jensen, J. R. Sensoriamento Remoto do Ambiente: uma perspectiva em recursos terrestres. 2ed. São José dos Campos: Parêntese, 2009, 604 p.

Moreira, M. A. Fundamentos do sensoriamento remoto e metodologias de aplicação. Editora Universidade Federal de Viçosa, 2012250 p. 
Oliveira,B; Verola, G. A. Avaliação do desempenho dos classificadores Isoseg e Bhattacharya para o mapeamento de áreas de cana-de-açúcar no município de Barretos-SP In SIMPÓSIO BRASILEIRO DE SENSORIAMENTO REMOTO - SBSR, 15,2013, Foz do Iguaçu. Anais... São José dos Campos, INPE, 2013, p. 89 - 96. Disponível em < http://www.dsr.inpe.br/sbsr2013/files/p0863.pdf > Acesso em 20/01/2017.

Prefeitura Municipal de Cardoso Moreira. Disponível em: 〈http://www.cardosomoreira.rj.gov.br/portal/index.php > Acesso em 20/01/2017.

United States Geological Survey, What are the best spectral bands to use for my study?,. Disponível em: < https://landsat.usgs.gov/what-are-best-spectral-bands-use-my-study >. Acesso em 25/1/2017 